\title{
Photoelectrode Fabrication of Dye-Sensitized Nanosolar Cells Using Multiple Spray Coating Technique
}

\author{
Chien-Chih Chen ${ }^{1}$ and Chen-Ching Ting ${ }^{2}$ \\ ${ }^{1}$ Department of Mechanical Engineering, National Taipei University of Technology, Taipei 10608, Taiwan \\ ${ }^{2}$ Institute of Mechanical and Electrical Engineering, National Taipei University of Technology, Taipei 10608, Taiwan \\ Correspondence should be addressed to Chien-Chih Chen; t8669030@ntut.edu.tw
}

Received 3 May 2013; Revised 19 June 2013; Accepted 25 June 2013

Academic Editor: Yuexiang Li

Copyright (c) 2013 C.-C. Chen and C.-C. Ting. This is an open access article distributed under the Creative Commons Attribution License, which permits unrestricted use, distribution, and reproduction in any medium, provided the original work is properly cited.

\begin{abstract}
This paper presents a spray coating technique for fabricating nanoporous film of photoelectrode in dye-sensitized nanosolar cells (DSSCs). Spray coating can quickly fabricate nanoporous film of the photoelectrode with lower cost, which can further help the DSSCs to be commercialized in the future. This paper analyzed photoelectric conversion efficiency of the DSSCs using spray coated photoelectrode in comparison with the photoelectrode made with the doctor blade method. Spray coating can easily control transmittance of the photoelectrode through the multiple spray coating process. This work mainly used a dispersant with help of ultrasonic oscillation to prepare the required nano- $\mathrm{TiO}_{2}$ solution and then sprayed it on the ITO glasses. In this work, a motoroperated conveyor belt was built to transport the ITO glasses automatically for multiple spray coating and drying alternately. Experiments used transmittance of the photoelectrode as a fabrication parameter to analyze photoelectric conversion efficiency of the DSSCs. The influencing factors of the photoelectrode transmittance during fabrication are the spray flow rate, the spray distance, and the moving speed of the conveyor belt. The results show that DSSC with the photoelectrode transmittance of ca. 68.0 $\pm 1.5 \%$ and coated by the spray coating technique has the best photoelectric conversion efficiency in this work.
\end{abstract}

\section{Introduction}

Dye absorbs photon energy of the incident light and causes its own electrons to be excited. The excited electrons in the dye then jump into the conduction band of the $\mathrm{TiO}_{2}$ and further run away from the photoelectrode into outer circuit $[1,2]$. This process indicates the fact that the larger the contact surface area between $\mathrm{TiO}_{2}$ and dye in DSSC, the larger the output current. In general, DSSC uses the photoelectrode of nanoporous $\mathrm{TiO}_{2}$ film to enlarge its contact surface with the dye [3]. In other words, developing an excellent technique for fabrication of the nanoporous $\mathrm{TiO}_{2}$ film is very important. Some methods have already existed, for example, doctor blade, electrophoresis, spin coating, and so forth, in the laboratory, which are not convenient for rapid and mass production [4-8].

A standard procedure for fabrication of the photoelectrode in DSSC is the first to generate the semiconductor layer on a conduction substrate, for example, the nanoporous $\mathrm{TiO}_{2}$ film on ITO glass; it is then immersed into dye solution for absorbing the dye. A nanoporous $\mathrm{TiO}_{2}$ film with suitable density is significant for better joint among the nanoparticles and better absorption of the largest amounts of dye $[9,10]$. The smaller the density of the nanoporous $\mathrm{TiO}_{2}$ film, the larger the absorbed amounts of the dye. The small density of the nanoporous $\mathrm{TiO}_{2}$ film has large pores, which is better to absorb the dye, but it is bad for the joint of the nanoparticles due to the large interspace among the nanoparticles.

In general, the nanoporous film generated by spray coating technique has smaller density due to its uncompressed fabrication process. Moreover, due to the advantages of quick fabrication and low cost of equipments, the spray coating technique is highly developed and widely applied in many surface coating applications, especially in the fields of automation and aerospace [11]. Okuya et al. in 2002 presented an industrial fabrication method using spray pyrolysis deposition technique to prepare porous $\mathrm{TiO}_{2}$ film for application in the DSSC [12]. The reached photoelectric 
conversion efficiency of DSSC was only 3.2\%, but it offered the feasibility of an industrial production for the DSSC by using spray pyrolysis technique. Fujihara et al. in 2007 used a cheap spray deposition technique for large area coating of $\mathrm{TiO}_{2}$ electrode in DSSC [13]. The new method removed the adhesion difficulties of longer nanofibers developed by the electrospinning technique with the conductive glass plate.

Summarizing the previous studies receives the following significant results for applying the spray coating technique. In general, little restriction to shape of substrate, easy control of parameters, upscaling possible, and so forth are the common benefits of the spray coating techniques, but using spray pyrolysis technique usually requires corrosive salts and thermal treatment up to ca. $500^{\circ} \mathrm{C}$ [14]. That is, the spray coating technique can quickly and cheaply build the nanoporous $\mathrm{TiO}_{2}$ films, which is suitable for the industrial requirements. The joint among the nanoparticles using the spray coating technique is weaker, which should be improved. This work presents a multiple spray coating technique for fabrication of the photoelectrode in DSSC using the homemade automation equipment with alternating spray coating and drying processes. The spray coating technique has generally many advantages, for example, quick manufacturing, easy transmittance controlling, convenient investigation for nanoporous film with multilayer, and so on. An automation spray coating apparatus and some instruments for measuring the transmittance, the $I-V$ curve, the IPCE, and so forth are built in this work. The main experimental parameter in this work is light transmittance of the photoelectrode in DSSC, which is produced by controlling the spray coating time. In principle, the larger the light transmittance, the smaller the thickness of the nano- $\mathrm{TiO}_{2}$ film in photoelectrode.

\section{Experimental Details}

2.1. Home-Made DSSCs. The main constituents of a standard DSSC arranged in a sequence from the light injection are the transparent conduction substrate, the photoelectrode, the dye, the electrolyte, and the counter electrode. The photoelectrode is a nanoporous semiconductor layer with the $\mathrm{TiO}_{2}$ nanopowder (P25, Degussa) in this work. Figure 1 shows structure of the home-made DSSC, and Table 1 is its structural specifications [15]. The nano- $\mathrm{TiO}_{2}$ solution for spray coating is prepared by mixing the $\varnothing=21 \mathrm{~nm} \mathrm{TiO}_{2}$ nanopowder (P25, Degussa) with dispersant of TritonX-100 and deionized water. The mixed $\mathrm{TiO}_{2}$ solution is then put into the ultrasonic cleaner for dispersion shaking.

2.2. Spray Coating Apparatus. The home-made automation spray coating apparatus is mainly composed of the spray box and the thermal drying oven, where the spray box and the thermal drying oven are connected with the conveyor belt. In process, the ITO glasses with conduction side upwards are first fixed on the conveyor belt and spray coated in the spray box. The spray coated ITO glasses are then sent into the thermal drying oven through the conveyor belt after every spray. Spray and drying are performed alternately in this process until it reaches the required transmittance.
TABLE 1: Structural specifications of the home-made DSSC.

\begin{tabular}{|c|c|}
\hline Component & Specification \\
\hline ITO glass & $\begin{array}{l}0.7 \mathrm{~mm} \text { thickness, } 10 \text { superficial } \\
\text { impedance. }\end{array}$ \\
\hline Semiconductor electrode & $\begin{array}{l}1 \mathrm{~g} \mathrm{TiO}_{2} \text { nanopowder (P25, Degussa), } \\
4 \mathrm{~mL} \text { deionized water, } 0.1 \mathrm{~g} \\
\text { TritonX-100, } 90 \text { mins, and } 400^{\circ} \mathrm{C} \\
\text { heating. }\end{array}$ \\
\hline Dye & $2.5 \mathrm{mM}$ alizarin yellow. \\
\hline Electrolyte & $\begin{array}{l}0.05 \mathrm{M} \mathrm{I}_{2} \text { and } 0.5 \mathrm{M} \mathrm{KI} \text { in solvent with } \\
\text { ethylene carbonate and propylene } \\
\text { carbonate. }\end{array}$ \\
\hline Counter electrode & $\begin{array}{l}0.8 \mathrm{~g} \text { Seedchem } \emptyset=22 \mathrm{~nm}, 0.2 \mathrm{~g} \mathrm{TiO} \\
\text { nanopowder }(\mathrm{P} 25, \text { Degussa }), 4 \mathrm{~mL} \\
\text { deionized water, } 0.1 \mathrm{~g} \text { ELASOL AS, } \\
60 \text { mins, and } 400^{\circ} \mathrm{C} \text { heating. }\end{array}$ \\
\hline
\end{tabular}

The experimental parameter is the transmittance of the photoelectrode. The adjustable conditions in this work are the moving speed of the conveyor belt, the spray flow rate, and the spray distance. An optimal condition in the homemade automation spray coating apparatus is found as follows: the moving speed of the conveyor belt is $9.47 \mathrm{~cm} / \mathrm{sec}$, the spray flow rate is $1.92 \times 10^{-4} \mathrm{~m}^{3} / \mathrm{sec}$, and the spray distance is $20 \mathrm{~cm}$. Figure 2 shows schema of the home-made automation spray coating apparatus. The spray box is connected with the negative pressure system to avoid leakage of the nanoparticles during spray coating. The float nanoparticles in the spray box during spray coating are absorbed by the negative pressure system and guided into water in the tank. In this work, the coated area is $2 \times 2 \mathrm{~cm}^{2}$, and an air spray nozzle is applied. Figure 3 shows a photo of the home-made automation spray coating apparatus.

Moreover, the doctor blade method was also applied for data comparing purpose, which used different thicknesses of guiding frame to control the transmittance and the coated area of the photoelectrode. The nano- $\mathrm{TiO}_{2}$ solution was first put onto the ITO glass and uniformly scraped by using the doctor blade method. A guiding frame was built in square area of $2 \times 2 \mathrm{~cm}^{2}$ using the $3 \mathrm{M}$ tape in this work. Figure 4 shows fabrication schema of the doctor blade method.

\subsection{Transmittance and I-V Curve Measurements. Measuring} the light transmittance used the solar meter integrated with the light source of $150 \mathrm{~W}$ metal halide lamp. Figure 5 shows schema of the light transmittance measurements for photoelectrode.

In process, the power of light $W_{A}$ is set as reference and detected by the solar meter without any hindrance. The power of light $W_{B}$ is measured while the light runs through the photoelectrode. Transmittance $(T)$ of the photoelectrode is determined in terms of the following:

$$
T=\frac{W_{B}}{W_{A}} \times 100 \% .
$$



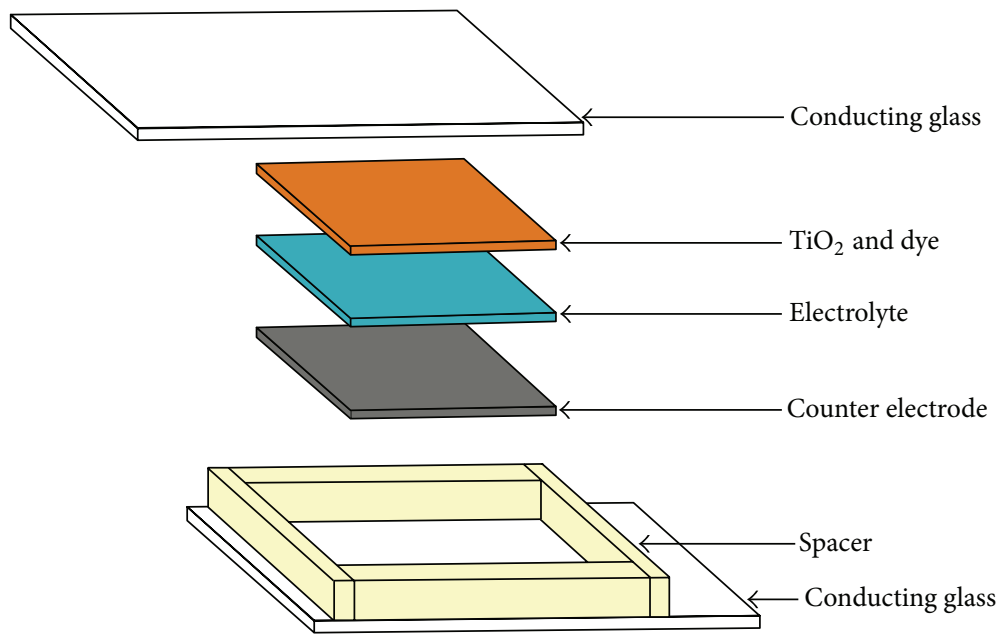

Figure 1: Structure of the home-made DSSC.

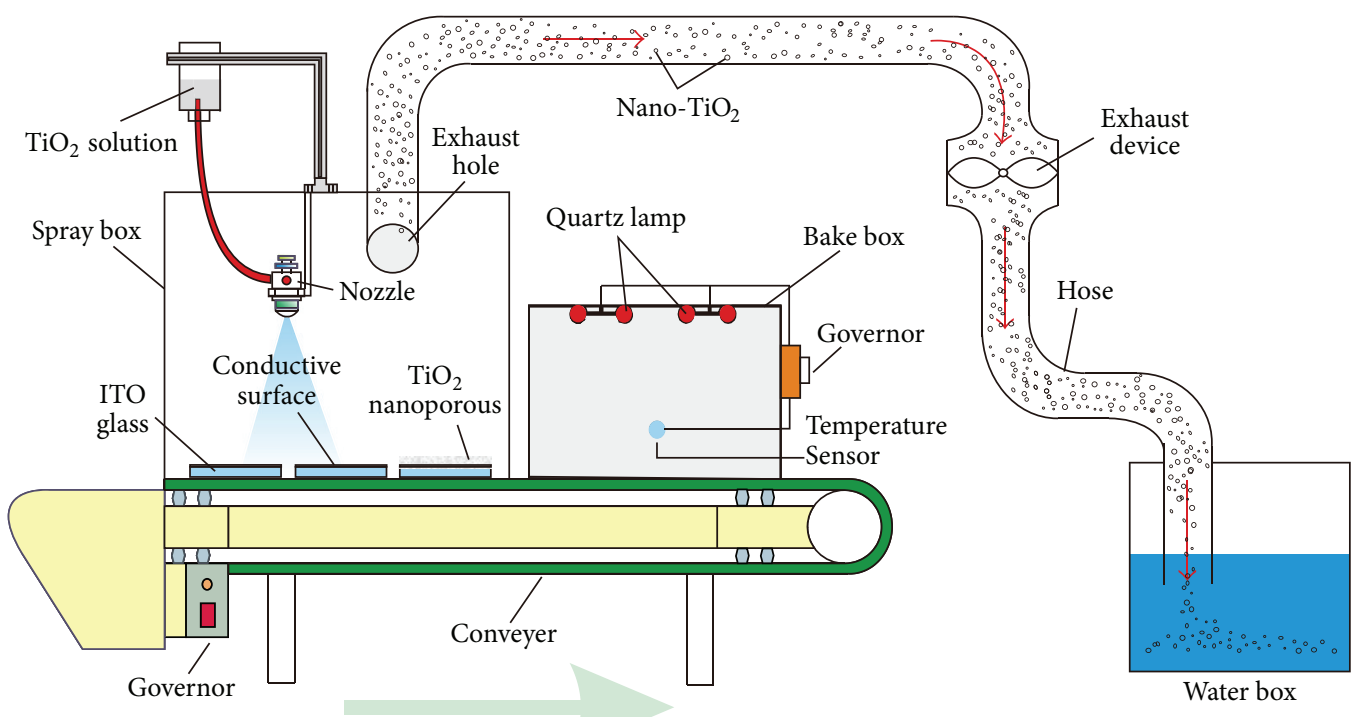

FIGURE 2: Schema of the home-made spray coating system.

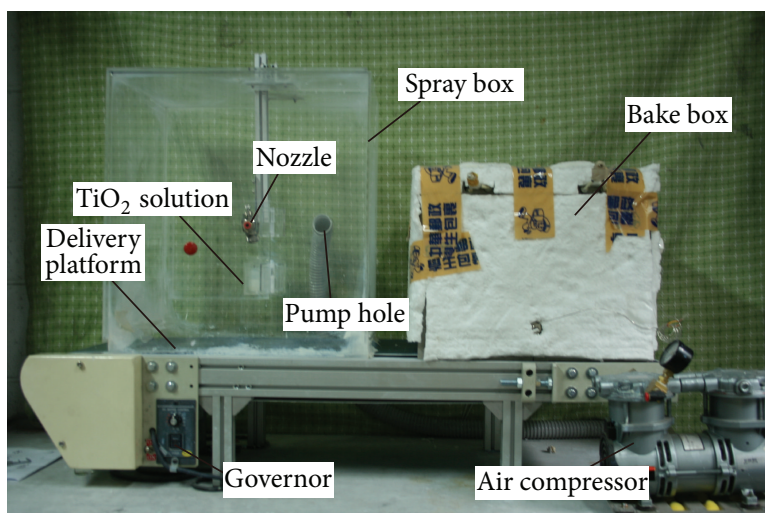

FIGURE 3: Setup photo of the home-made spray coating system. 

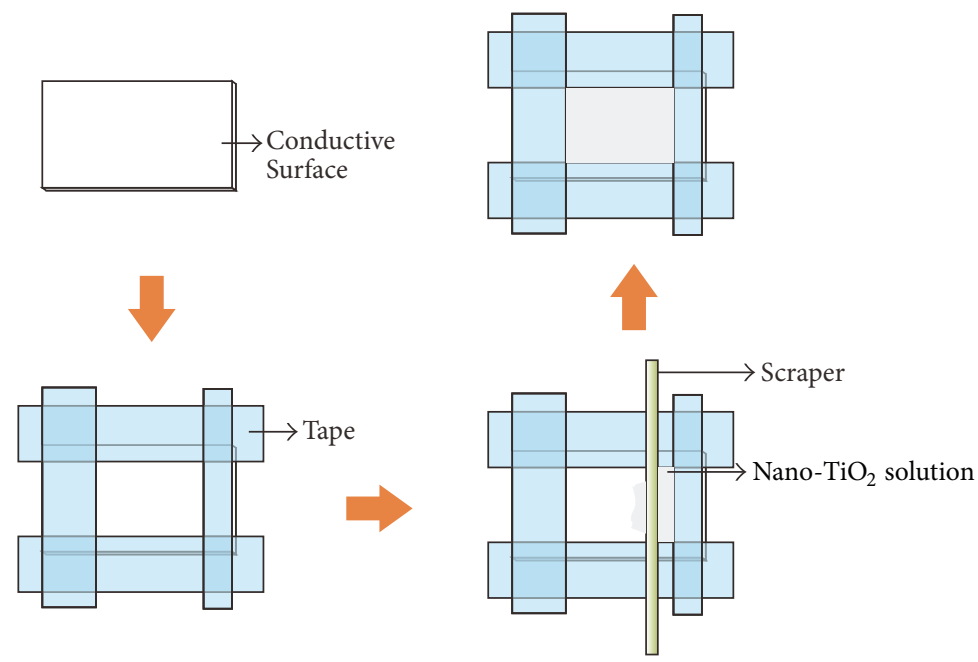

FIGURE 4: Fabrication schema of the doctor blade method.
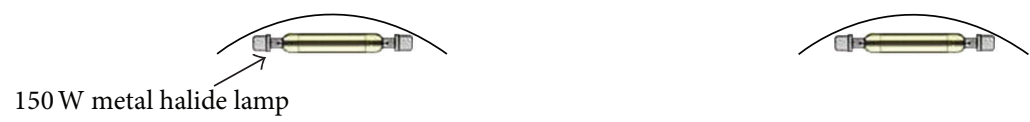

$150 \mathrm{~W}$ metal halide lamp
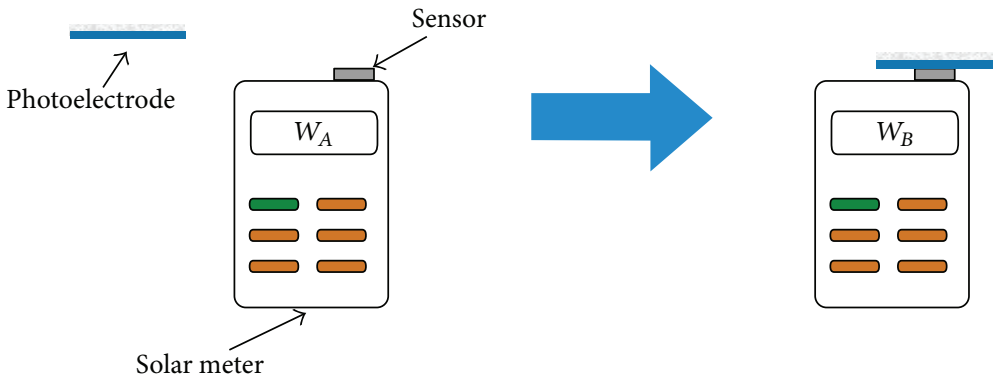

FIGURE 5: Schema of the light transmittance measurements for photoelectrode.

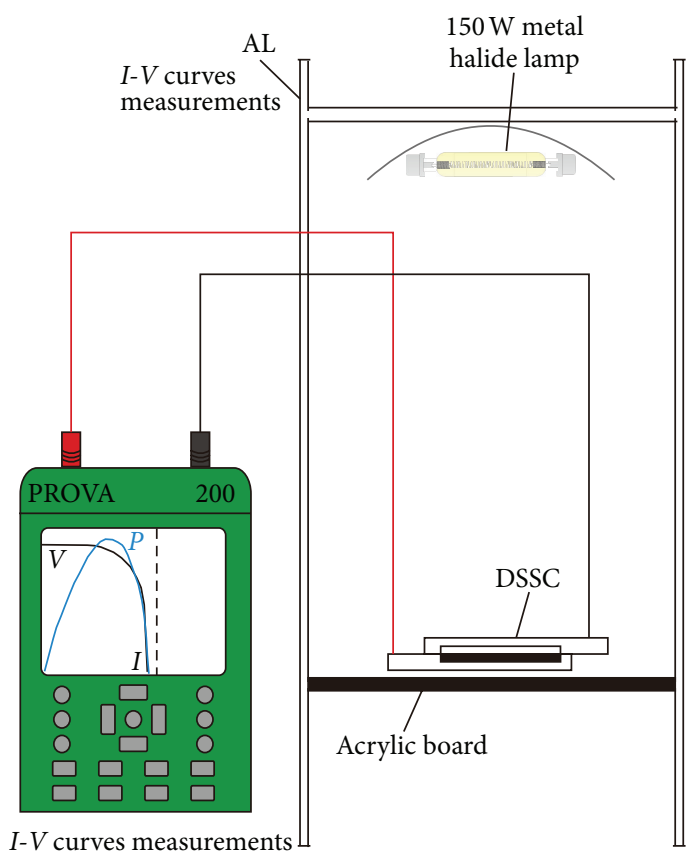

FIgURE 6: Schema of the $I-V$ curve measurements. 


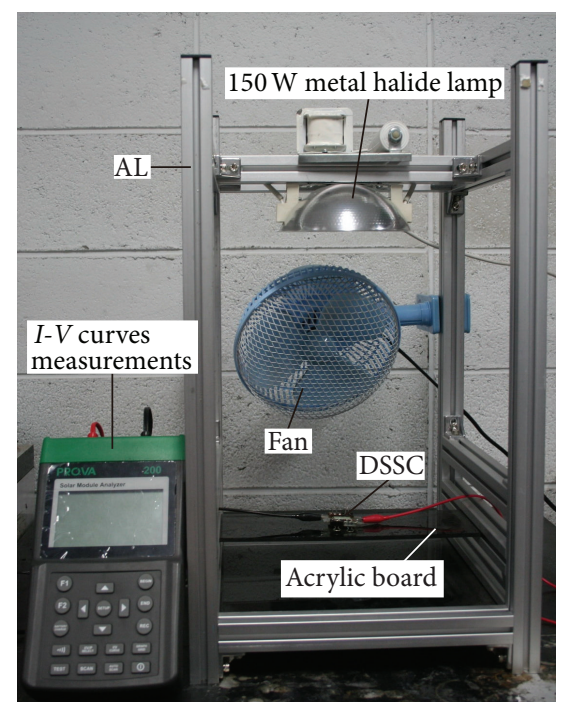

FIGURE 7: Setup photo of the $I-V$ curve measurements.

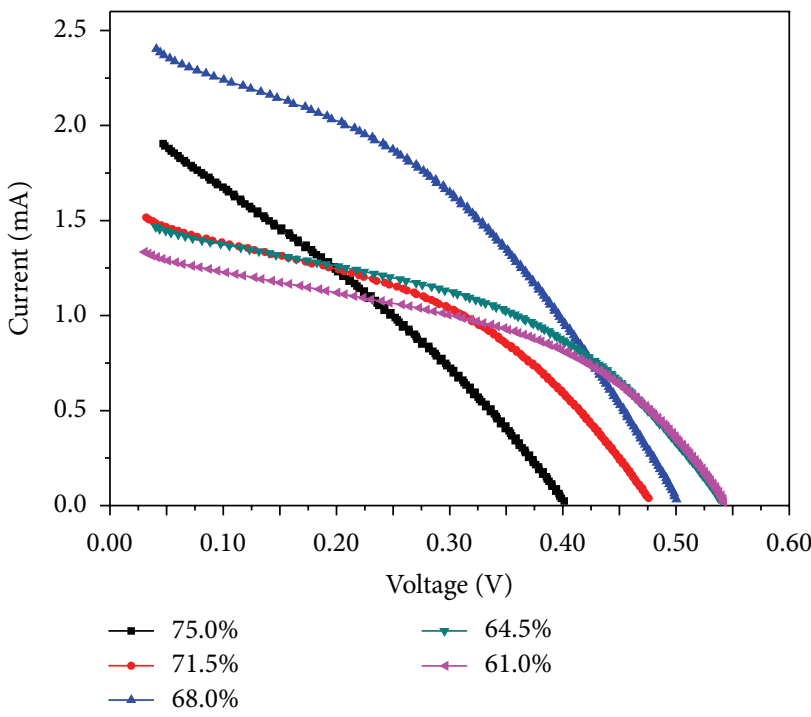

(a) Multiple spray coating technique

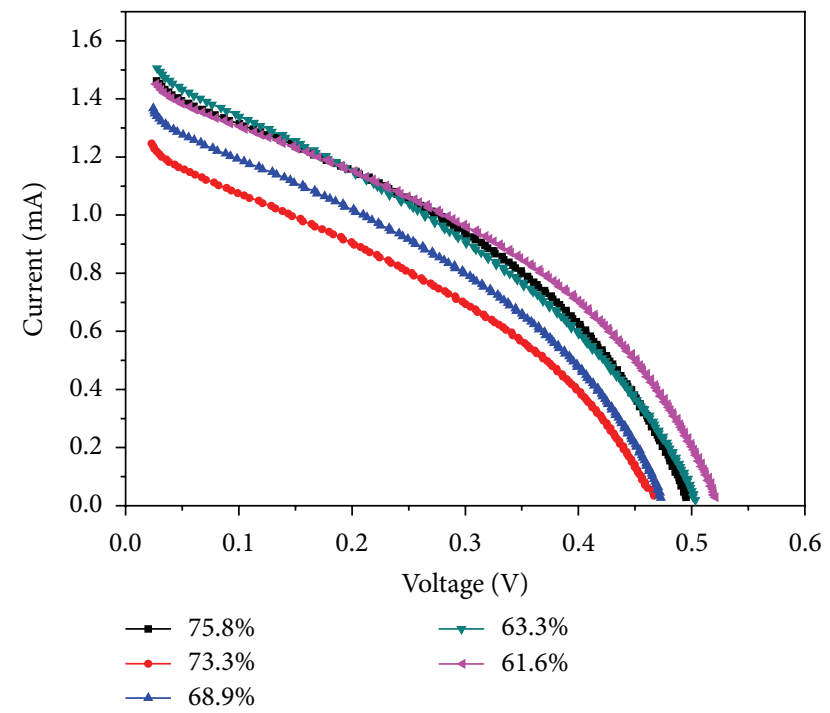

(b) Doctor blade method

FIGURE 8: $I-V$ curves of the DSSCs.

Moreover, the $I-V$ curves of DSSCs are measured with condition at a temperature of $30 \pm 1^{\circ} \mathrm{C}$ for photoelectric conversion efficiency analysis. The applied home-made apparatus is composed of an adjustable electric resistance, an electric meter, and a $1000 \mathrm{~W} / \mathrm{m}^{2}$ metal halide lamp. In principle, the output voltage and current are measured by changing value of the electric resistances in the apparatus. The measured voltage is the open-circuit voltage $\left(V_{\mathrm{oc}}\right)$, and the current is the shortcircuit current $\left(I_{\mathrm{sc}}\right)$ [15]. A compact $I-V$ values capturing instrument of PVORA200 with $150 \mathrm{fps}$ resolution, voltage range of 1-10 V, and current range of 3-30 mA was integrated with the light source of $150 \mathrm{~W}$ metal halide lamp for $I-V$ curve measurements in this work. Figure 6 shows schema of the $I$ $V$ curve measurements, and Figure 7 is photo of the homemade apparatus.

\section{Results and Discussion}

This work aims to develop the multiple spray coating technique for quickly fabricating the photoelectrode of DSSC, which is for purpose of the commercialization. The present study shows the $I-V$ curves comparison of DSSCs by changing the light transmittance of photoelectrode fabricated by multiple spray coating technique and doctor blade method. Table 2 shows transmittances of the made photoelectrode using the multiple spray coating technique and the doctor blade method in this work.

Figure 8 shows $I-V$ curves of the DSSCs, where Figure 8 (a) used the multiple spray coating technique, and Figure 8(b) used the doctor blade method. Figure 8(a) indicates that the $I-V$ curves are strongly influenced by 


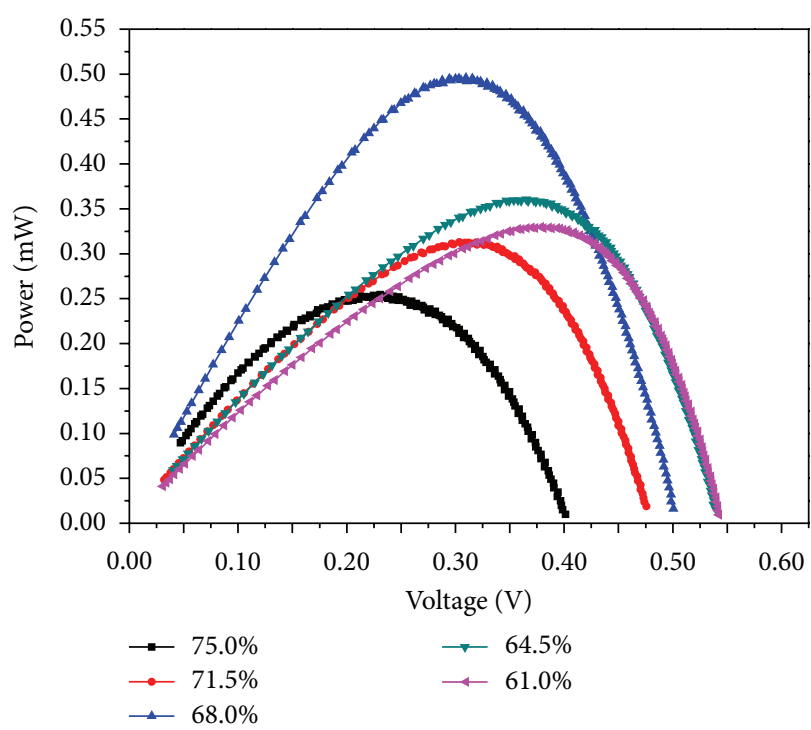

(a) Multiple spray coating technique

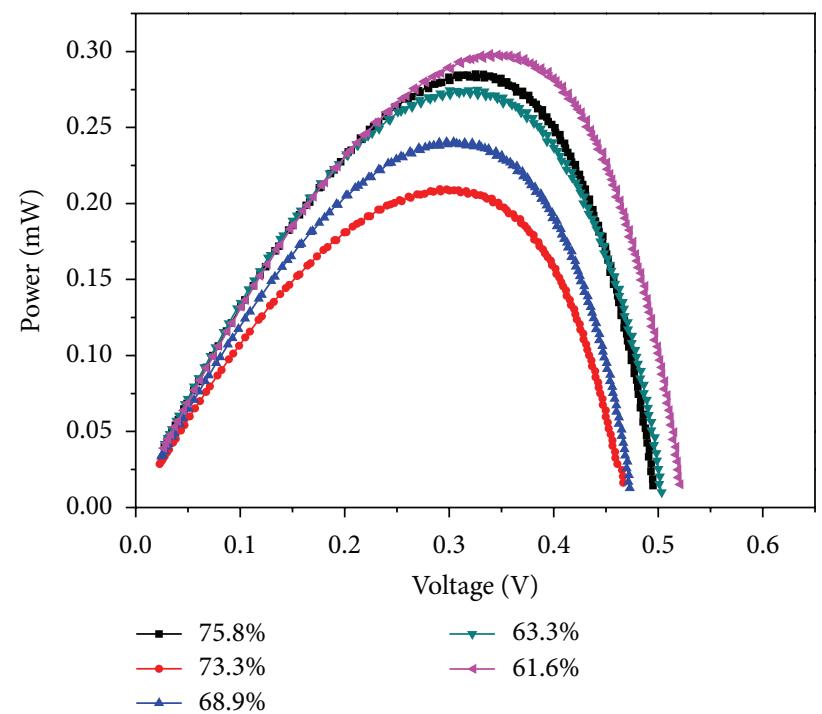

(b) Doctor blade method

Figure 9: $P-V$ curves of the DSSCs.

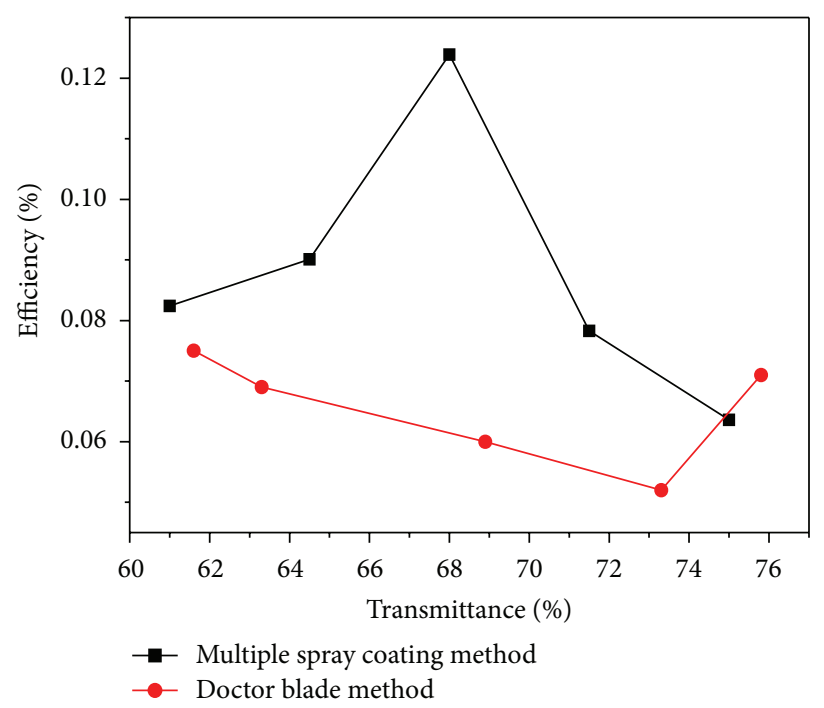

FIGURE 10: Photoelectric conversion efficiency distribution of DSSCs influenced by photoelectrode transmittance using different coating techniques.

TABLE 2: Transmittance of the photoelectrode.

\begin{tabular}{lc}
\hline Technique & Transmittance $(\%)$ \\
\hline Spray coating & $61.0,64.5,68.0,71.5,75.0$ \\
Doctor blade & $61.6,63.3,68.9,73.3,75.8$ \\
\hline
\end{tabular}

transmittance of the photoelectrode using the multiple spray coating technique. The best photoelectric conversion is found in Figure 8(a) with the photoelectrode transmittance of ca. $68.0 \pm 1.5 \%$. Moreover, Figure 8(b) exhibits that influence of the photoelectrode transmittance is not very clear by using the doctor blade method in comparison with Figure 8(a). A better photoelectric conversion is found in Figure 8(b) with the photoelectrode transmittance of ca. $61.6 \pm 1.5 \%$.
Figure 9 further shows $P-V$ curves of the DSSCs, where Figure 9 (a) used the multiple spray coating technique, and Figure 9(b) used the doctor blade method. Figure 9 clearly indicates that the maximum output power in Figure 9(a) is ca. $0.4957 \mathrm{~mW}$ and in Figure 9(b) is ca. $0.2983 \mathrm{~mW}$. In other words, the output power with optimal photoelectrode transmittance using the multiple spray coating technique is almost double better than using the doctor blade method. Figure 10 shows photoelectric conversion efficiency distribution influenced by the photoelectrode transmittance. The optimal transmittance for the multiple spray coating technique is ca. $68.0 \pm 1.5 \%$. The photoelectric conversion efficiencies are declined while the transmittance is away from the optimal transmittance. Larger transmittance means fewer nanoparticles of $\mathrm{TiO}_{2}$, which further receives the smaller current. 


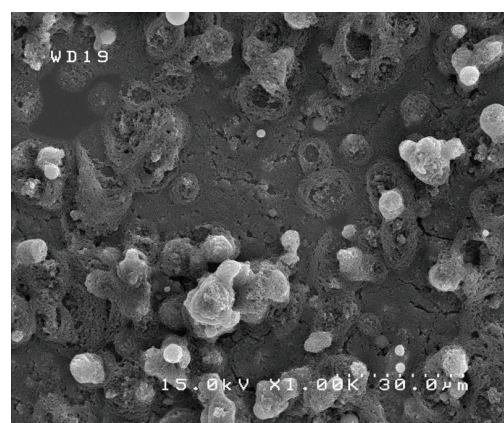

(a) Photoelectrode transmittance of ca. 75.0 $\pm 1.5 \%$

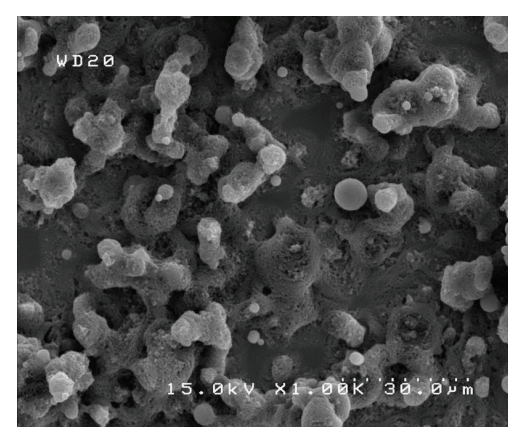

(b) Photoelectrode transmittance of ca. 68.0 $\pm 1.5 \%$

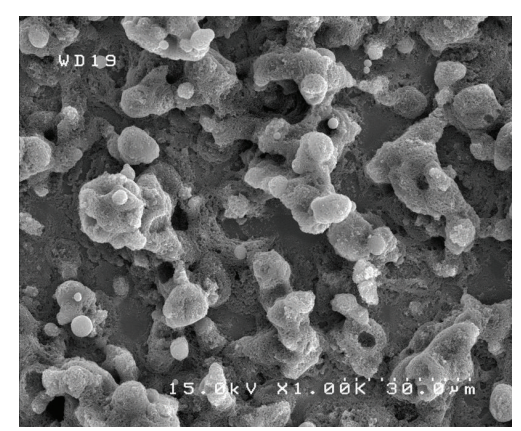

(c) Photoelectrode transmittance of ca. 64.5 $\pm 1.5 \%$

FIGURE 11: SEM images of $\mathrm{TiO}_{2}$ layer coated by the multiple spray coating technique.

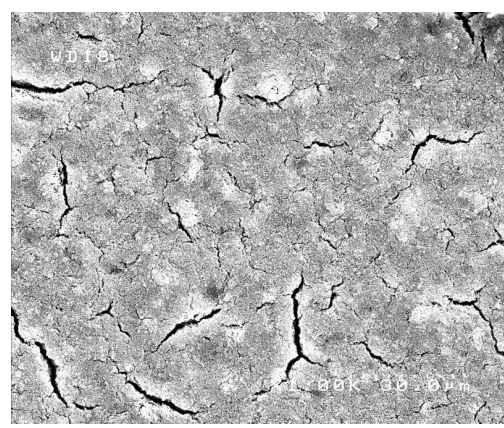

(a) Photoelectrode transmittance of ca. 75.8 $\pm 1.5 \%$

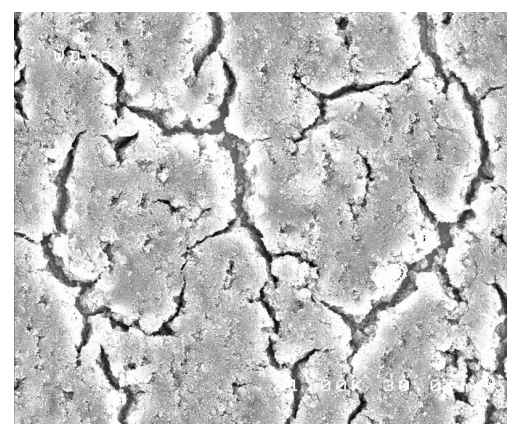

(b) Photoelectrode transmittance of ca. 68.9 $\pm 1.5 \%$

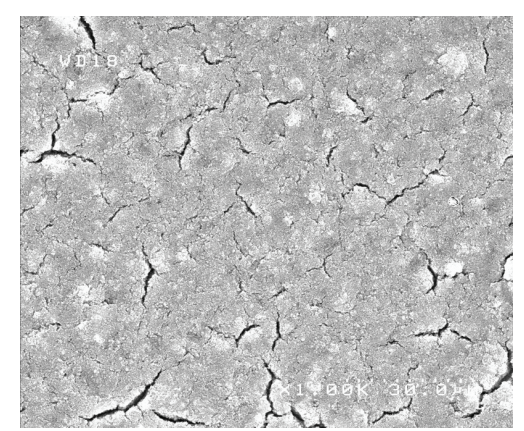

(c) Photoelectrode transmittance of ca. 63.3 $\pm 1.5 \%$

Figure 12: SEM images of $\mathrm{TiO}_{2}$ layer coated by the doctor blade method.

Oppositely, smaller transmittance means more nanoparticles of $\mathrm{TiO}_{2}$, which hinders the incident light to reach the back dye. Therefore, the results show that the larger or the smaller the transmittance, the smaller the photoelectric conversion efficiency.

Figures 11 and 12 show SEM images of the $\mathrm{TiO}_{2}$ layer in different transmittances, where Figure 11 is produced by the multiple spray coating technique, and Figure 12 is made by the doctor blade method. Figure 11 clearly indicates that the nanoparticles of $\mathrm{TiO}_{2}$ are arranged sparsely. In other words, the dye can easily infiltrate into the $\mathrm{TiO}_{2}$ layer. Oppositely, Figure 12 exhibits that the nanoparticles of $\mathrm{TiO}_{2}$ are arranged close together. This arrangement will cause the dye to infiltrate into the $\mathrm{TiO}_{2}$ layer difficultly. The larger amounts of dye infiltrated into the $\mathrm{TiO}_{2}$ layer, the larger the photoelectric conversion efficiency in the optimal transmittance.

\section{Conclusion}

An automation multiple spray coating and drying apparatus has been successfully built for preparing the $\mathrm{TiO}_{2}$ layer of the photoelectrode. The results show that an optimal transmittance for the multiple spray coating technique is ca. $68.0 \pm 1.5 \%$ and for the doctor blade method is ca. $61.6 \pm 1.5 \%$, where the photoelectric conversion efficiencies are ca. $0.124 \%$ and $0.075 \%$, respectively. The photoelectric conversion efficiencies are declined while the transmittance is away from the optimal transmittance. The results indicate that the multiple spray coating technique can replace the doctor blade method for fabrication of $\mathrm{TiO}_{2}$ layer in DSSC.

\section{Acknowledgments}

The authors would like to acknowledge the financial support from the National Science Foundation and under Grants no. NSC101-2622-E-027-002-CC2 and no. NSC101-2221-E-027036-NSC102-2622-E-027-002-CC2.

\section{References}

[1] R. Memming and H. Tributsch, "Electrochemical investigations on the spectral sensitization of gallium phosphide electrodes," Journal of Physical Chemistry, vol. 75, no. 4, pp. 562-570, 1971.

[2] C.-C. Ting and W.-S. Chao, "The reversal constituent structure of photo-electrode in dye-sensitized solar cells," Journal of Alloys and Compounds, vol. 509, no. 35, pp. 8670-8675, 2011.

[3] B. O’Regan and M. Grätzel, "A low-cost, high-efficiency solar cell based on dye-sensitized colloidal $\mathrm{TiO}_{2}$ films," Nature, vol. 353, no. 6346, pp. 737-740, 1991.

[4] Y. Li, J. Hagen, W. Schaffrath, P. Otschik, and D. Haarer, "Titanium dioxide films for photovoltaic cells derived from a sol gel process," Solar Energy Materials and Solar Cells, vol. 56, no. 2, pp. 167-174, 1999. 
[5] G. P. Smestad, "Education and solar conversion: demonstrating electron transfer," Solar Energy Materials and Solar Cells, vol. 55, no. 1-2, pp. 157-178, 1998.

[6] D. Gutiérrez-Tauste, I. Zumeta, E. Vigil, M. A. HernándezFenollosa, X. Domènech, and J. A. Ayllón, "New lowtemperature preparation method of the $\mathrm{TiO}_{2}$ porous photoelectrode for dye-sensitized solar cells using UV irradiation," Journal of Photochemistry and Photobiology A, vol. 175, no. 2-3, pp. 165-171, 2005.

[7] T.-V. Nguyen, H.-C. Lee, and O.-B. Yang, "The effect of prethermal treatment of $\mathrm{TiO}_{2}$ nano-particles on the performances of dye-sensitized solar cells," Solar Energy Materials and Solar Cells, vol. 90, no. 7-8, pp. 967-981, 2006.

[8] Y.-M. Sung and H.-J. Kim, "Sputter deposition and surface treatment of $\mathrm{TiO}_{2}$ films for dye-sensitized solar cells using reactive RF plasma," Thin Solid Films, vol. 515, no. 12, pp. 49964999, 2007.

[9] N.-G. Park, J. van de Lagemaat, and A. J. Frank, "Comparison of dye-sensitized rutile- and anatase-based $\mathrm{TiO}_{2}$ solar cells," Journal of Physical Chemistry B, vol. 104, no. 38, pp. 8989-8994, 2000.

[10] Y. Ohsaki, N. Masaki, T. Kitamura et al., "Dye-sensitized $\mathrm{TiO}_{2}$ nanotube solar cells: fabrication and electronic characterization," Physical Chemistry Chemical Physics, vol. 7, no. 24, pp. 4157-4163, 2005.

[11] S. Barradas, R. Molins, M. Jeandin et al., "Application of laser shock adhesion testing to the study of the interlamellar strength and coating-substrate adhesion in cold-sprayed copper coating of aluminum," Surface and Coatings Technology, vol. 197, no. 1, pp. 18-27, 2005.

[12] M. Okuya, K. Nakade, and S. Kaneko, "Porous $\mathrm{TiO}_{2}$ thin films synthesized by a spray pyrolysis deposition (SPD) technique and their application to dye-sensitized solar cells," Solar Energy Materials and Solar Cells, vol. 70, no. 4, pp. 425-435, 2002.

[13] K. Fujihara, A. Kumar, R. Jose, S. Ramakrishna, and S. Uchida, "Spray deposition of electrospun $\mathrm{TiO}_{2}$ nanorods for dyesensitized solar cell," Nanotechnology, vol. 18, no. 36, Article ID 365709, 5 pages, 2007.

[14] H. A. Hamedani, "Investigation of deposition parameters in ultrasonic spray pyrolysis for fabrication of solid oxide fuel cell cathode," Tech. Rep., George W. Woodruff School of Mechanical Engineering, Georgia Institute of Technology, 2008.

[15] Y.-S. Chen, J.-N. Lee, S.-Y. Tsai, and C.-C. Ting, "Manufacture of dye-sensitized nano solar cells and their I-V curve measurements," Materials Science Forum, vol. 594, pp. 324-330, 2008. 

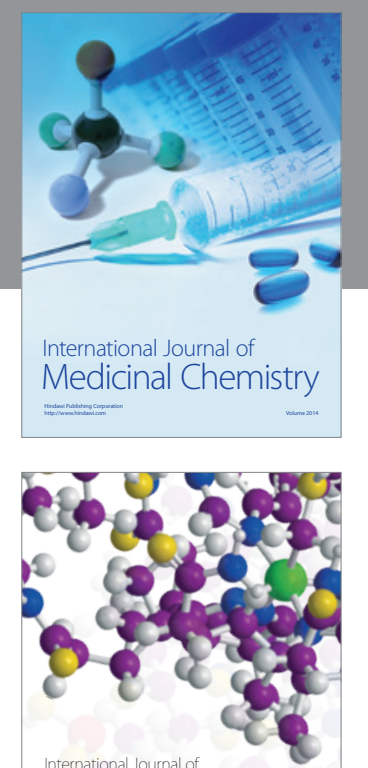

\section{Carbohydrate} Chemistry

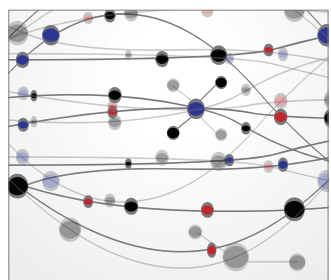

The Scientific World Journal
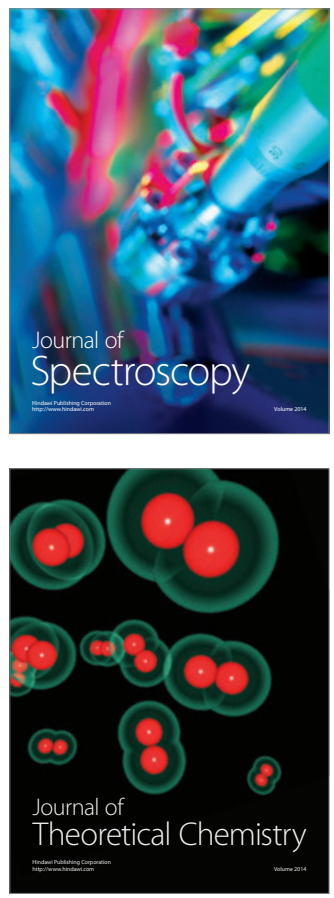
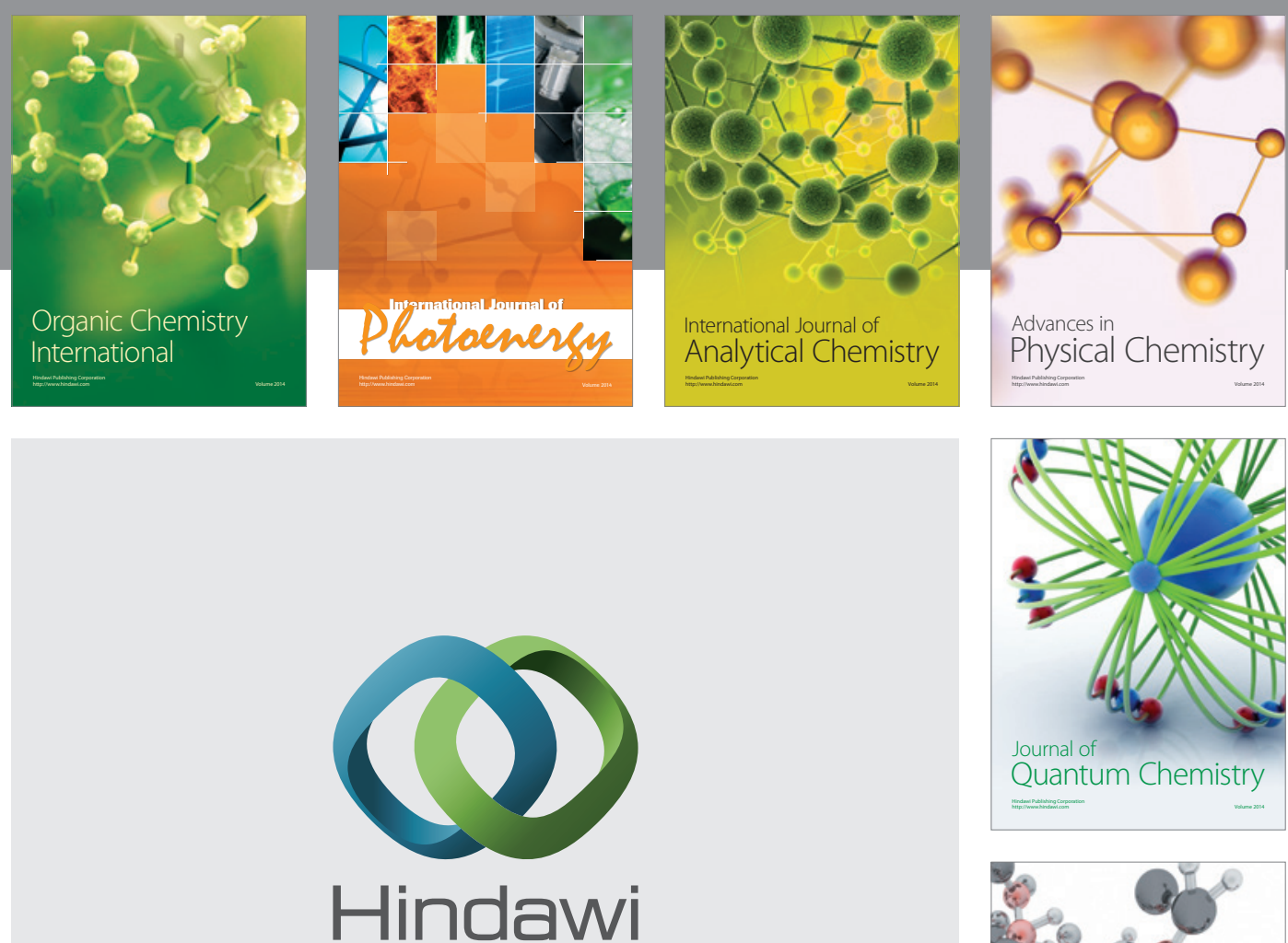

Submit your manuscripts at

http://www.hindawi.com

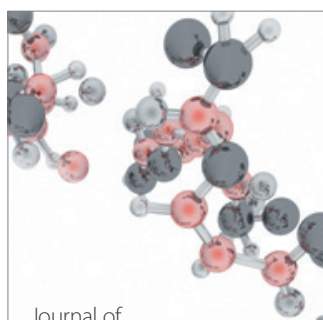

Analytical Methods

in Chemistry

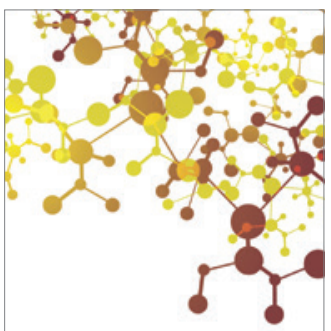

Journal of

Applied Chemistry

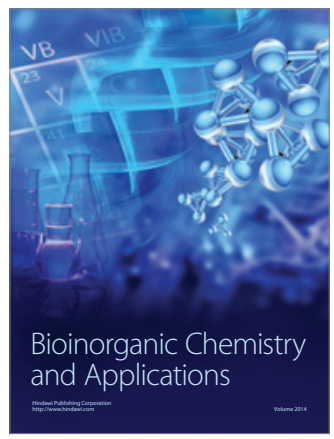

Inorganic Chemistry
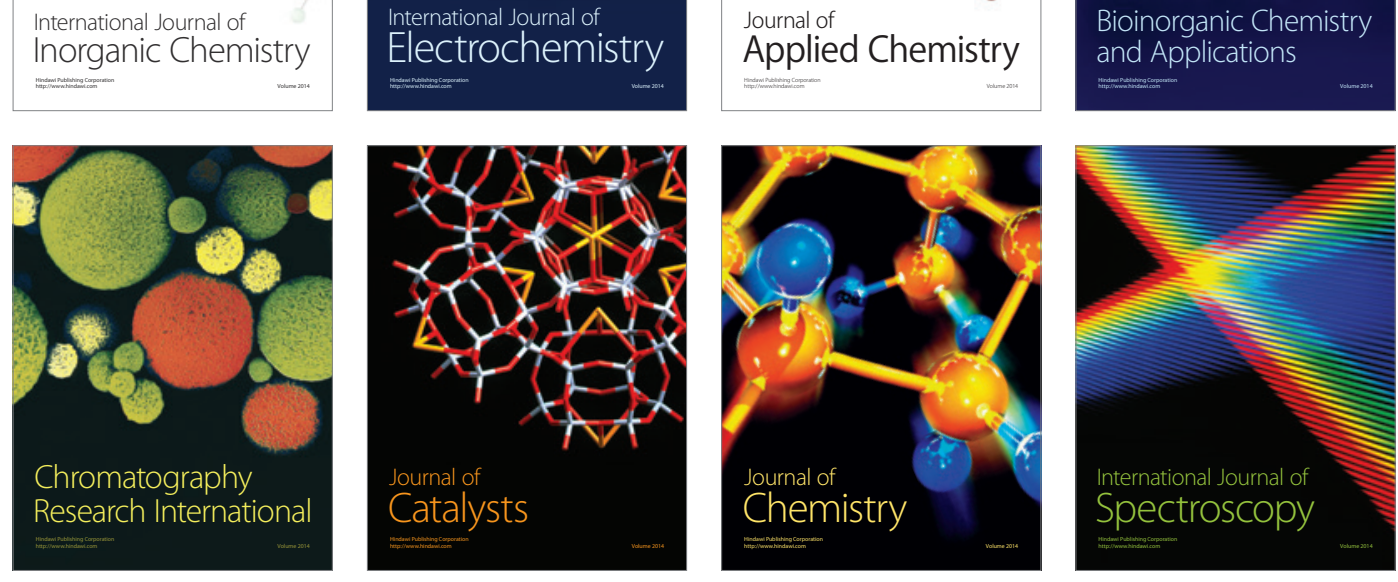